\title{
Solid Pseudopapillary Neoplasm of the Pancreas: Experience of a Tertiary Hospital
}

\author{
Tiago Bouça-Machado ${ }^{1}$, Renato Bessa-Melo ${ }^{1}$, Joanne Lopes ${ }^{2}$, Luís Graça ${ }^{1}$, José Costa-Maia ${ }^{1}$
}

Corresponding author:

Tiago Bouça Machado, MD

Alameda Prof. Hernâni Monteiro

4200-319 Porto, Portugal

Phone +351225512100

Fax number +351225025 766

E-mail: tiagobouca@gmail.com

Received: 05.11.2019

Accepted: 20.02.2020

$\overline{\text { Copyright } \odot \text { Celsius Publishing House }}$ www.sgo-iasgo.com
${ }^{1}$ General Surgery Department, Hospital Săo Joăo, Porto, Portugal

${ }^{2}$ Department of Anatomic Pathology, Hospital Săo Joăo, Porto, Portugal

\section{ABSTRACT}

Background: Solid pseudopapillary neoplasm of pancreas is a rare tumor, predominantly affecting young women, usually with a favorable prognosis.

Methods: We present a retrospective observational case-series study of eight patients diagnosed and treated in a dedicated hepatobiliary and pancreatic unit, describing the clinicopathological and immunohistochemical features.

Results: seven patients were female, with a mean age of 31 years; the most frequently performed procedure was distal pancreatectomy in six cases. The lesions were well defined, with solid or mixed aspects, with $57,6 \mathrm{~mm}$ average size. Average follow-up is 88 months without disease recurrence or mortality records during that period.

Conclusion: Given the rarity of these neoplasms, its orientation should be made only in referral centers, with multidisciplinary teams committed to pancreatic pathology.

Key words: solid pseudopapillary, pancreas neoplasm, pancreatectomy, progesterone receptors

\section{INTRODUCTION}

Solid pseudopapillary neoplasm of pancreas (SPNP) is a rare tumor, with low aggressive behavior, corresponding to 0,3 to $2,7 \%$ of all pancreatic tumors (1-3). Ninety per cent of the patients are female, between the second and fourth decade of life $(1,4,5)$.

These tumors arise as solid mass that suffers degeneration by vascularization alterations assuming the characteristic pseudopapillary pattern and cystic spaces (6). Given the different macroscopic aspect, that can present as a solid, cystic or with both components (4), this entity was known under different names as papillary epithelial neoplasm, papillary cystic neoplasm, solid and papillary epithelial neoplasm, solid and cystic acinar cell tumor, papillary cystic epithelial neoplasm, solid and cystic tumor, solid and papillary neoplasm, low grade papillary neoplasm, and Frantz's tumor $(1,3,7,8)$. Despite some previous reports of SPNP, its recognition as a distinct entity was described by Franz in 1959 (9). It was not until 1996 that the World Health Organization (WHO) defined this entity as SPNP (10).

There has been an increase in incidence of this entity in the last two decades, 
most likely due to an increased diagnostic yield, with the use of more sophisticated image methods, than a real incidence increase (5). As a result, more SPNP were diagnosed in asymptomatic patients, and the tumor size tended to be smaller (5).

Despite the significant size this type of tumor can exhibit, it is frequently asymptomatic but may present with abdominal pain or palpable mass (5). Due to its rarity and uncommon clinical presentation, this entity offers a diagnostic and therapeutic challenge.

This article describes eight cases of SPNP treated in a specialized hepatobiliary and pancreatic unit between 2006 and 2016.

\section{METHODS}

A retrospective observational case-series study was conducted with patients having histologically confirmed SPNP, submitted to surgical treatment between 2006 and 2016. Data were collected retrospectively by reviewing the clinical file for clinical presentation, imaging exams, surgical procedure, histologic examination and immunohistochemistry analysis. Postoperative complications were also reviewed and categorized according to Clavien classification (11).

\section{RESULTS}

Eight patients with the diagnosis of SPNP, submitted to pancreatic resection, were identified in the study period. Seven were female, with a mean age of 31 years (minimum 16; maximum 42).

The tumors were located in the tail in four patients, in the body in two cases and in the head of pancreas in the other two cases. None of the patients had distant metastasis at time of diagnosis. In preoperative study, computed tomography (CT) scan was performed in seven patients (figs. 1, 2) and magnetic resonance image (MRI) in one (fig. 3). A heterogeneous lesion in imaging study was present in five cases and in the other three appeared as a solid lesion. These three solid lesions were the smallest ones with size under $25 \mathrm{~mm}$.

Endoscopic ultra-sound guided fine needle biopsy (EUS-FNB) was performed in five cases with uncertain diagnosis (fig. 4), with diagnosis of SPNP in three, an inconclusive result in one and the other case was an

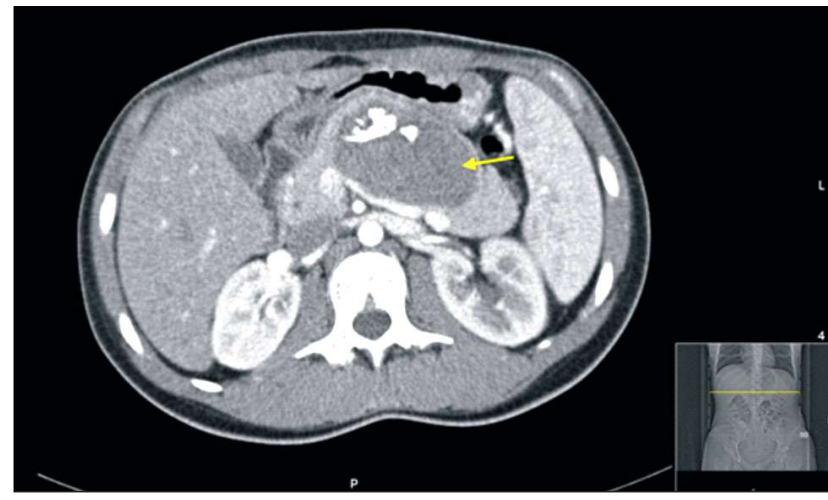

Figure 1 - CT scanning showing a SPNP (arrow indicating cystic component)

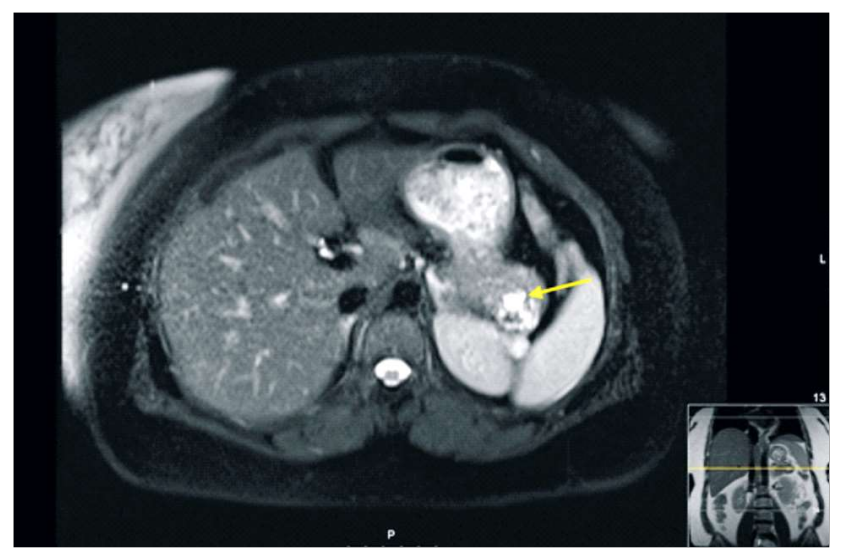

Figure 3 - MR scanning (T2) showing a SPNP (arrow indicating cystic component)

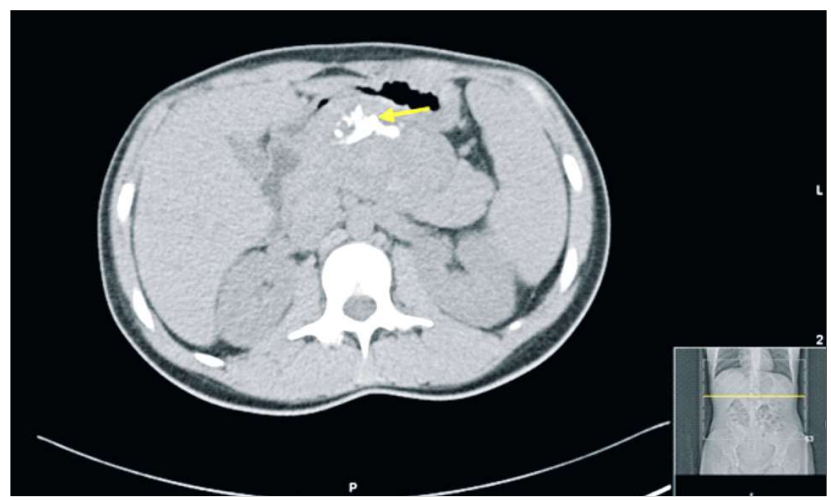

Figure 2 - Non-enhanced CT scanning showing a SPNP (arrow indicating calcifications)

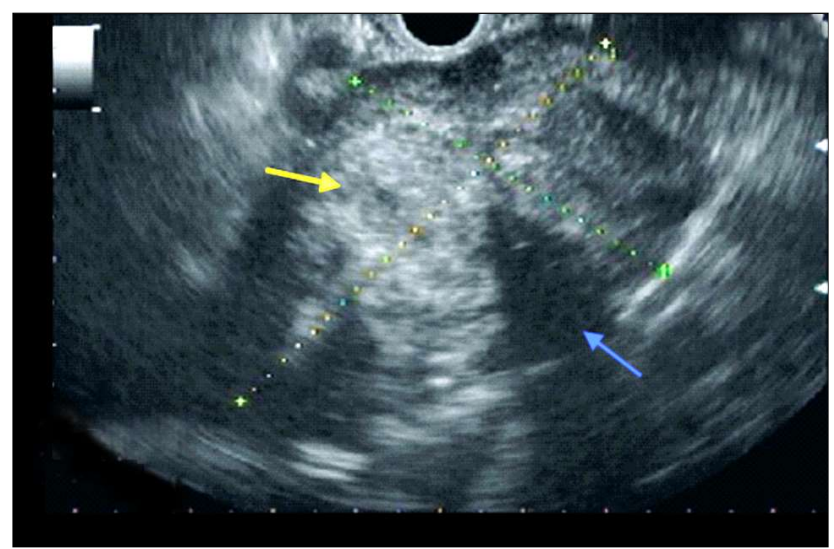

Figure 4 - EUS image of a heterogeneous SPNP (yellow arrow indicating the solid component, blue arrow indicating cystic component) 
erroneous result of gastro intestinal stromal tumor (GIST). Surgical indications were GIST, solid mass suspect of malignancy in three cases and four SPNP.

Distal pancreatectomy (DP) was performed in six cases, with spleen preservation in one. In two patients, with the lesion located in the head of pancreas, a pancreatoduodenectomy (PD) was performed (table 1). In three pancreatosplenectomies and one spleen preserving distal pancreatectomy a laparoscopic approach was used.

One patient developed a pancreatic fistula grade B according to the ISGPF classification (12), corresponding to grade II complication, according to the Clavien classification. There were no other complications or mortality.

Macroscopically, all lesions were well defined, with solid or mixed aspect, with $57,6 \mathrm{~mm}$ average dimension (minimum 18; maximum 140). Average lymph node harvested was 5 (minimum 0; maximum 13). Pathologic report revealed two cases with peripancreatic fat invasion, one case with vascular, lymphatic and perineural invasion and one with peripancreatic fat, vascular and perineural invasion (table 2). Immunohistochemistry study was conducted in all cases and is depicted in table 3 (figs. 5-8).

Average follow up is 88 months (minimum 32;

Table 1 - Patients' characteristics

\begin{tabular}{|c|c|c|c|c|c|c|}
\hline Case & Gender & Age (years) & Location & Size $(\mathrm{mm})$ & Procedure & Laparoscopic \\
\hline 1 & $f$ & 34 & Head & 25 & Pancreatoduodenectomy & No \\
\hline 2 & $f$ & 42 & Body & 18 & Pancreatosplenectomy & No \\
\hline 3 & f & 20 & Tail & 45 & Spleen-preserving pancreatectomy & Yes \\
\hline 4 & f & 16 & Tail & 80 & Pancreatosplenectomy & Yes \\
\hline 5 & $\mathrm{~m}$ & 33 & Tail & 140 & Pancreatosplenectomy & No \\
\hline 6 & f & 36 & Head & 18 & Pancreatoduodenectomy & No \\
\hline 7 & f & 24 & Body & 95 & Pancreatosplenectomy & Yes \\
\hline 8 & $f$ & 41 & Tail & 40 & Pancreatosplenectomy & Yes \\
\hline
\end{tabular}

Table 2 - Histologic invasion results

\begin{tabular}{|c|c|c|c|c|}
\hline Case & Size (mm) & Vascular invasion & Perineural invasion & Peripancreatic fat invasion \\
\hline 1 & 25 & - & - & - \\
\hline 2 & 18 & - & - & - \\
\hline 3 & 45 & - & - & + \\
\hline 4 & 80 & - & - & - \\
\hline 5 & 140 & + & + & + \\
\hline 6 & 18 & - & + & + \\
\hline 7 & 95 & + & + & - \\
\hline 8 & 40 & - & - & - \\
\hline
\end{tabular}

Table 3 - Immunohistochemistry results

\begin{tabular}{|c|c|c|c|c|c|c|c|c|}
\hline Case & CD56 & CD10 & Progesterone & Vimentin & Alpha-1-antitrypsin & Estrogen & Synaptophysin & Chromogranin \\
\hline 1 & + & + & + & + & + & - & + & - \\
\hline 2 & + & + & + & $\mathrm{N} / \mathrm{A}$ & $\mathrm{N} / \mathrm{A}$ & $\mathrm{N} / \mathrm{A}$ & + & - \\
\hline 3 & + & + & + & $\mathrm{N} / \mathrm{A}$ & + & - & - & - \\
\hline 4 & + & + & + & + & $N / A$ & - & + & $\mathrm{N} / \mathrm{A}$ \\
\hline 5 & + & + & + & + & + & $\mathrm{N} / \mathrm{A}$ & + & - \\
\hline 6 & + & + & + & $\mathrm{N} / \mathrm{A}$ & $\mathrm{N} / \mathrm{A}$ & $\mathrm{N} / \mathrm{A}$ & + & - \\
\hline 7 & + & + & + & + & $N / A$ & $N / A$ & + & - \\
\hline 8 & + & + & + & $\mathrm{N} / \mathrm{A}$ & $\mathrm{N} / \mathrm{A}$ & $\mathrm{N} / \mathrm{A}$ & + & - \\
\hline
\end{tabular}




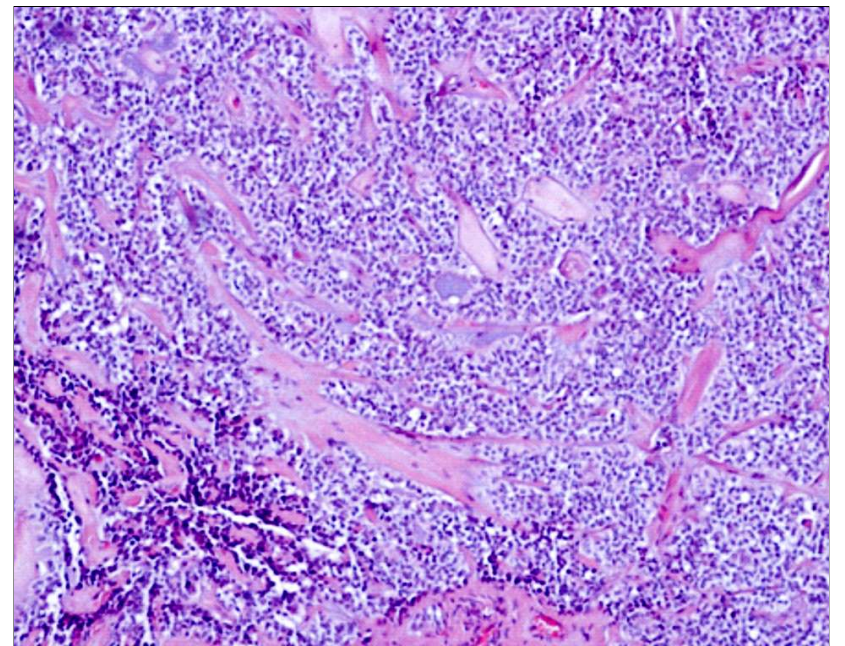

Figure 5 - Solid nests of poorly cohesive cells surrounding blood vessels, resulting in a pseudopapillary architecture and stromal hyalinization (H\&E, $x 100)$

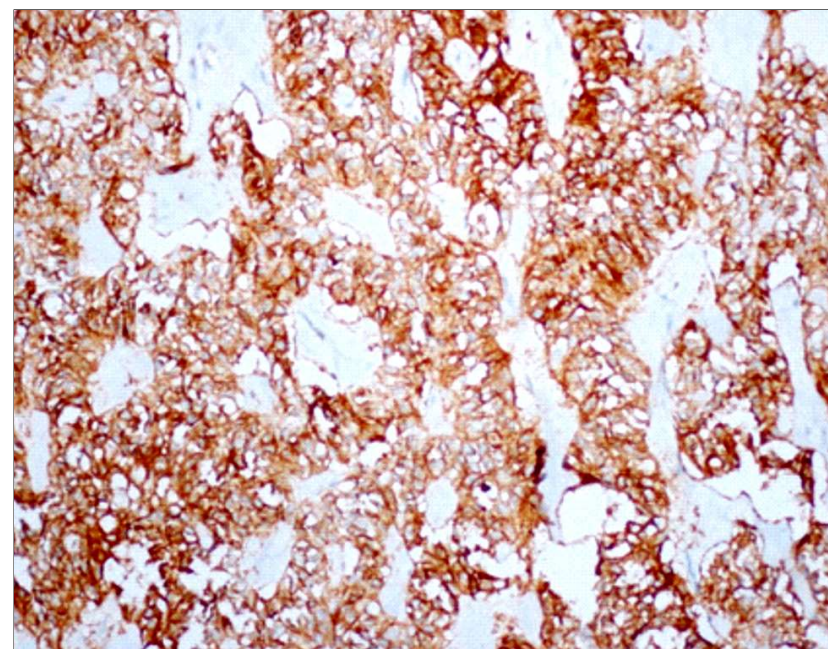

Figure 7 - Immunohistochemistry showing staining for CD56 (X 200)

maximum 158) without any evidence of recurrence or death during this period.

\section{DISCUSSION}

SPNP are rare pancreatic tumors presenting mainly in young women. In our study, seven of eight patients were female, with an average age of 31 years, in accordance with the literature, despite case reports of ages between 2 and 85 years (13). According to Limaiem et al. male patients tend to be older than female patients (14) with our male patient older than the average female age.

Most patients mention unspecific symptoms, while the rest are asymptomatic and accidentally diagnosed

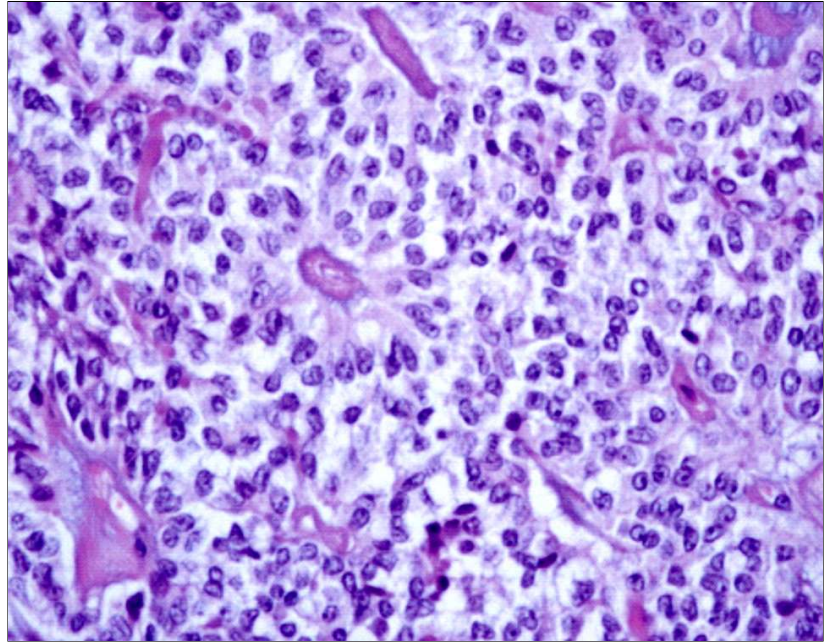

Figure 6 - Tumor cells have moderate amount of eosinophilic cytoplasm and relatively uniform bland nuclei, inconspicuous nucleoli and characteristic longitudinal grooves (H\&E, X400)

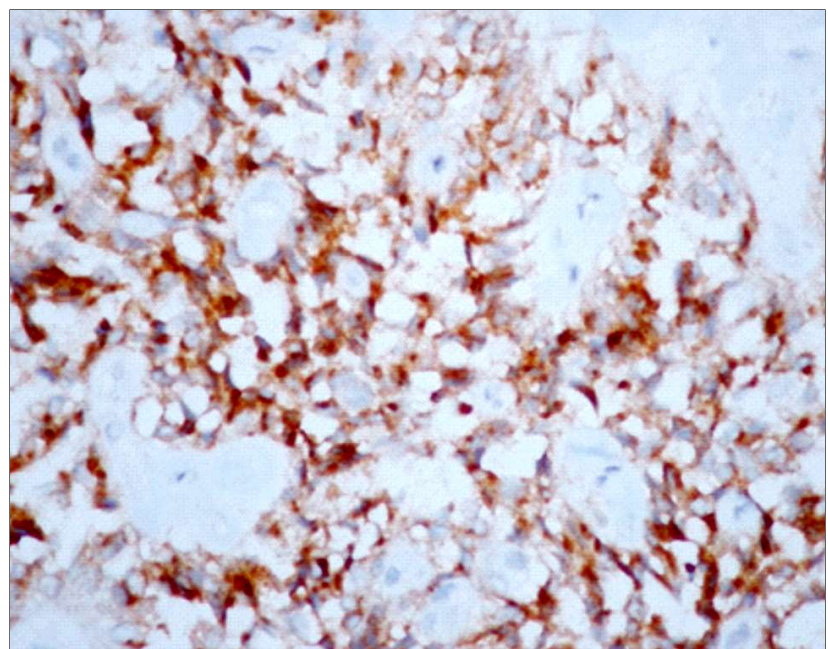

Figure 8 - Immunohistochemistry showing staining for CD10 (X 200)

$(15,16)$. Abdominal pain or painless palpable abdominal mass is the commonest presentation, as occurred in our series. These tumors are usually incidental findings in radiologic exams performed by other reasons or during the study of unspecific abdominal symptoms (13). Most symptoms described in the literature as pain, nausea, vomits, early satiety are related to the mass effect. Less frequently, patients present with jaundice or hemoperitoneum by compression of the bile duct or tumor rupture, respectively (13).

This neoplasia can occur in any location within the pancreas, but more frequently occurs in the distal pancreas $(5,17)$. In our patients, four were located in the tail, two in the body and two in the head of the pancreas. 
The usual aspect of this entity is a solid tumor with a cystic component, determined by its size. Smaller tumors usually presents as solid but less circumscribed while larger ones presents with a fibrous pseudocapsule, friable areas, cystic degeneration and hemorrhage $(1,4,18)$. Calcification can be observed and the majority is located in the lesion's periphery or solid areas of the lesion $(4,19)$. Cystic degeneration can be exuberant and simulate a pseudocyst $(6,13)$.

Pancreatic neuroendocrine tumors (PNET) can mimic SPNP, particularly when they are cystic or when SPNP are predominantly solid (20). The differential diagnosis of SPNP should also include pancreatoblastoma and acinar cells carcinoma $(13,15)$.

Fine needle biopsy (FNB) should be very well considered once there are reported cases of seeding along the needle track (21). A pancreatic mass with both solid and cystic components, in young patients, should evoke the diagnosis (22). On the other hand, the radiologic aspect of these tumors can reproduce any pancreatic tumor with areas of necrosis, usually seen in large PNET. In this setting, FNB is useful in the diagnosis with therapeutic implications and has complication rate as low as $1 \%$ to $2 \%(23,24)$. FNB was performed in five cases with one erroneous diagnosis of GIST and one inconclusive diagnosis. According to Lubezky et al. the sensitivity of this procedure is $90.9 \%$ (5). FNB should only be performed if there is considerable doubt in the diagnostic and if the histologic result alters the therapeutic decision.

Surgical treatment consists in complete excision but parenchyma-sparing procedures are the gold standard. Depending on the location and proximity to Wirsung duct, the recommended procedure can be enucleation, DP, central pancreatectomy or PD. In our series, distal pancreatectomy was the most common procedure with six cases, with two PD performed. Lymph node dissection is not justifiable (15) since lymph node metastasis rate is lower than $0,6 \%(1,25,26)$. In a recent article, Jutric et al reviewing 340 patients reports an unusual lymph node metastasis percentage of $12 \%(17)$. In our series, the mean of lymph nodes harvested was five with no metastasis. This number is inferior to the optimal cut-points suggested by L. Huang, et al (27) because only three cases had a pre-operative malignant suspicious.

When the tumor is confined to the pancreas, with complete excision, the cure rate is around 95\% $(5,28)$. There is no evidence of recurrence in our patients, with a mean follow-up of 88 months. About
10 to $15 \%$ of patients develop metastasis $(17,26$, 29-32), with the liver and peritoneum being the most frequent locations (5).

There is no literature consensus regarding the surgical treatment of metastasis. Some authors state that excision therapy is the best treatment for liver metastasis $(1,5)$. On the contrary, Jutric et al. reports that patients with distant metastasis who did not undergo surgical resection experienced a greater median survival compared with the ones submitted to surgical treatment (17). Patients with nonresectable disease or metastasis can achieve a longterm survival $(17,32)$ and so the use of other treatment modalities, such as arterial chemoembolization, radiotherapy or even liver transplant, should be weighted (26).

A regular follow-up is mandatory because early diagnosis of a possible local or distant relapse may be compatible with a significant survival, provided the best therapeutic alternative is applied.

The cellular origin has not yet been elucidated (33) and do not resemble any cell type of the adult or embryological pancreas. Some authors have proposed an extra-pancreatic origin of this tumor, namely an origin in pluripotential cells (34) or primitive ovarian cells (35-37). Kosmahl et al. suggested that cells from the primitive gonads might migrate to the developing pancreas since genital ridges are very close to the pancreatic anlage during embryogenesis (38). Michalova et al. recently proposed that SPNP, primary signet ring stromal tumor of the testis, solid pseudopapillary neoplasm of the ovary, and pancreatic analogue solid pseudopapillary neoplasm of the testis are similar tumors, representing the same entity occurring in different organs (33).

Some authors advocate the presence of a hormonal mechanism in the tumorigenesis of these lesions due to the relative frequency of such tumors in female patients and the high percentage of progesterone receptor (PR). In our series, all cases marked positively for $\mathrm{PR}$, what is slightly above the percentage described in the literature $(26,39)$. Despite the high frequency of PR positivity, no in vivo or in vitro study has demonstrated the dependence of its stimulation in the growth or survival of these tumors (29).

Numerous immunohistochemical markers were tested in SPNP. The most frequently found were: a1-antitrypsin, vimentin, $\alpha 1$-antichymotrypsin, neuron specific enolase (NSE), CD56 (NCAM), CD10 and PR (15, $26,30,39,40)$. In addition to $P R$, the most frequent immunohistochemical markers in our series were CD10, CD 56 (NCAM), vimentin, synaptophysin and 
alpha-1-antitrypsin. Notohara et al. suggest that SPNP exhibit a unique immunohistochemical expression of CD56 (NCAM), CD10, and focal expression of other neuroendocrine markers (41). The immunohistochemical markers are essential to differentiate SPNP from other neoplasm as PNET (42).

Prognostic criteria to predict malignant behavior are not well defined (29). According to the WHO classification, SPNP can be a solid pseudopapillary neoplasia with borderline malignant potential or solid pseudopapillary carcinoma (SPC). The criteria to classify as carcinoma are the presence of vascular, perineural or peripancreatic invasion $(39,43)$. Malignant SPNP occur in around $15 \%$ of adult patients $(39,43)$. In our study, four cases showed at least one criterion to be classified as carcinoma. According to Lubezky et al. the presence of malignant features is not associated with tumor size, but size is the most significant clinical feature associated with metastatic disease and lower disease-free survival (5). Size is also a prognostic factor to relapse, with some authors indicating a threshold of $50 \mathrm{~mm}$ (44) or $80 \mathrm{~mm}$ (25). In three cases, the tumors were larger than $80 \mathrm{~mm}$ and three of our four patients with vascular, perineural or peripancreatic invasion had tumor size larger than $45 \mathrm{~mm}$.

Despite the possibility of invasion and distant metastasis, given its indolent behavior, this tumor is considered to be of low malignant potential (13).

Lee et al. suggests that there are some radiologic features such as pancreatic duct dilation and vessel encasement, either with or without metastasis, that allow differentiation benign SPN from SPC and this implies a more aggressive surgical approach and an intensive follow-up (45).

\section{CONCLUSION}

SPNP predominantly affects young women and usually exhibits an indolent behavior. Resection is the only effective treatment and accountable for the good prognosis associated with this type of lesions. Given the morbidity and mortality associated with pancreatic surgery, the orientation of these patients should be made only in referral centers, with multidisciplinary teams committed to pancreatic pathology, as the treatment facility emerges as one of the few significant predictors of survival in this disease.

The definition of malignancy criteria is fundamental to determine the follow-up and prognosis of these patients.

Despite SPNP usually being large and "ugly" pancreatic lesions, they are usually ressectable and have a very good prognosis.

\section{Conflict of interest}

The authors declare that there are no conflicts of interests.

\section{REFERENCES}

1. Papavramidis T, Papavramidis S. Solid pseudopapillary tumors of the pancreas: Review of 718 patients reported in english literature. J Am Coll Surg. 2005;200(6):965-72.

2. Crawford $2^{\text {nd }} B E$. Solid and papillary epithelial neoplasm of the pancreas, diagnosis by cytology. South Med J. 1998;91(10):973-7.

3. Lam KY, Lo CY, Fan ST. Pancreatic solid-cystic-papillary tumor: clinicopathological features in eight patients from Hong Kong and review of literature. World J Surg. 1999;23(10):1045-50.

4. Fu XB, Hao ZQ, He JY, Shang H, Fu QC, Hua XD, et al. Pathology comparative study on the characteristic CT signs in solid pseudopapillary neoplasm of the pancreas. Exp Ther Med. 2017;13(6): 3523-8.

5. Lubezky N, Papoulas M, Lessing Y, Gitstein G, Brazowski E, Nachmany I, et al. Solid pseudopapillary neoplasm of the pancreas: Management and long-term outcome. Eur J Surg Oncol. 2017; 43(6):1056-60.

6. Hosokawa I, Shimizu H, Ohtsuka M, Kato A, Yoshitomi H, Furukawa $\mathrm{K}$, et al. Preoperative diagnosis and surgical management for solid pseudopapillary neoplasm of the pancreas. J Hepatobiliary Pancreat Sci. 2014;21(8):573-8.

7. Vijay A, Ram L, Mathew RK, Chawdhery MZ. Solid pseudopapillary tumor of the pancreas in a patient with cervical cancer: relation of $\mathrm{E}$-cadherin/ $\beta$-catenin adhesion complex in their carcinogenesis. $\mathrm{J}$ Surg case reports. 2015;2015(4):1-3.

8. Coleman K, Doherty M, Bigler S. Solid-Pseudopapillary Tumor of the Pancreas 1. Radiographics. 2003; 23(6):1644-8.

9. Franz V. Papillary tumors of the pancreas: benign or malignant. Frantz VK Atlas tumor Pathol Washingt DC US Armed Forces Inst Pathol. 1959;32-3.

10. Kloppel G, Solcia E, Longnecker DS, Capella C, Sobin LH. Histological classification of tumors of the exocrine pancreas. Histol Typing Tumors Exocrine Pancreas, 2nd Ed Springer-Verlag Berlin. 1996;7(10).

11. Dindo D, Demartines N, Clavien P-A. Classification of Surgical Complications. Ann Surg. 2004;240(2):205-13.

12. Bassi C, Marchegiani G, Dervenis C, Sarr M, Abu Hilal M, Adham M, et al. The 2016 update of the International Study Group (ISGPS) definition and grading of postoperative pancreatic fistula: 11 Years After. Surg (United States). 2017;161(3):584-91.

13. Chakhachiro Z, Zaatari G. Solid-pseudopapillary neoplasm A Pancreatic Enigma. Arch Pathol. 2009;1989-93.

14. Limaiem F, Mestiri H, Mejri S, Lahmar A, Mzabi S. Solid pseudopapillary neoplasm of the pancreas in two male patients: gender does not matter. Pan Afr Med J. 2017;27:283.

15. Vassos N, Agaimy A, Klein P, Hohenberger W, Croner RS. Solidpseudopapillary neoplasm (SPN) of the pancreas: case series and literature review on an enigmatic entity. Int J Clin Exp Pathol. 2013; 6(6):1051-9.

16. Suzuki S, Hatori T, Furukawa T, Shiratori K, Yamamoto M. Clinical and pathological features of solid pseudopapillary neoplasms of the pancreas at a single institution. Dig Surg. 2014;31(2):143-50.

17. Jutric Z, Rozenfeld Y, Grendar J, Hammill CW, Cassera MA, Newell $\mathrm{PH}$, et al. Analysis of 340 Patients with Solid Pseudopapillary Tumors of the Pancreas: A Closer Look at Patients with Metastatic Disease. Ann Surg Oncol. 2017;24(7):2015-22.

18. G. A, J. Z, N.E. A-H. Solid pseudopapillary neoplasm of the pancreas: 
CT imaging features and radiologic-pathologic correlation. Diagnostic Interv Radiol. 2017;23(2):94-9.

19. Buetow PC, Buck JL, Pantongrag-Brown L, Beck KG, Ros PR, Adair CF. Solid and papillary epithelial neoplasm of the pancreas: imaging-pathologic correlation on 56 cases. Radiology. 1996; 199(3):707-11.

20. Zhu L, Xue H dan, Liu W, Wang X, Sui X, Wang Q, et al. Enhancing pancreatic mass with normal serum CA19-9: key MDCT features to characterize pancreatic neuroendocrine tumours from its mimics. Radiol Medica. 2017;122(5):337-44

21. Pettinato G, Di Vizio D, Manivel JC, Pambuccian SE, Somma P, Insabato L. Solid-pseudopapillary tumor of the pancreas: A neoplasm with distinct and highly characteristic cytological features. Diagn Cytopathol. 2002;27(6):325-34.

22. Wang X, Liu X. Comments on "Solid pseudopapillary neoplasm of the pancreas: Management and long-term outcome." Eur J Surg Oncol. 2018;44(2):268-9.

23. Wang J, Zhao S, Chen Y, Jia R, Zhang X. Endoscopic ultrasound guided fi ne needle aspiration versus endoscopic ultrasound guided fi ne needle biopsy in sampling pancreatic masses. Medicine (Baltimore). 2017;96(28):e7452

24. Chen G, Liu S, Zhao Y, Dai M, Zhang T. Diagnostic accuracy of endoscopic ultrasound-guided fine-needle aspiration for pancreatic cancer: a meta-analysis. Pancreatology. 2013;13(3):298-304.

25. Kang CM, Choi SH, Kim SC, Lee WJ, Choi DW, Kim SW. Predicting recurrence of pancreatic solid pseudopapillary tumors after surgical resection: a multicenter analysis in Korea. Ann Surg. 2014;260(2): 348-55.

26. Yu P-F, Hu Z-H, Wang X-B, Guo J-M, Cheng X-D, Zhang Y-L, et al. Solid pseudopapillary tumor of the pancreas: a review of 553 cases in Chinese literature. World J Gastroenterol. 2010;16(10): 1209-14.

27. Huang L, Jansen L, Balavarca $Y$, van der Geest L, Lemmens V, Groot Koerkamp B, et al. Significance of Examined Lymph Node Number in Accurate Staging and Long-term Survival in Resected Stage I-II Pancreatic Cancer - More is Better? A Large International Population-based Cohort Study. Ann Surg. 2019 Aug 13. [Epub ahead of print]

28. Dinarvand P, Lai J. Solid Pseudopapillary Neoplasm of the Pancreas: A Rare Entity With Unique Features. Arch Pathol Lab Med. 2017; 141(7):990-5.

29. Reddy S, Wolfgang CL. Solid Pseudopapillary Neoplasms of the Pancreas. Adv Surg. 2009;43(1):269-82.

30. Reindl B a, Lynch DW, Jassim AD. Aggressive variant of a solid pseudopapillary neoplasm: a case report and literature review. Arch Pathol Lab Med. 2014;138(7):974-8.

31. Klimstra DS, Wenig BM, Heffess CS. Solid-pseudopapillary tumor of the pancreas: a typically cystic carcinoma of low malignant potential. Semin Diagn Pathol. 2000;17(1):66-80.

32. Tang LH, Aydin H, Brennan MF, Klimstra DS. Clinically aggressive solid pseudopapillary tumors of the pancreas: a report of two cases with components of undifferentiated carcinoma and a comparative clinicopathologic analysis of 34 conventional cases. Am J Surg Pathol. 2005;29(4):512-9.

33. Michalova K, Michal M, Kazakov DV, Sedivcova M, Hes 0, Hadravsky $\mathrm{L}$, et al. Primary signet ring stromal tumor of the testis: a study of 13 cases indicating their phenotypic and genotypic analogy to pancreatic solid pseudopapillary neoplasm. Hum Pathol. 2017; 67: 85-93.

34. Liu X, Rauch TM, Siegal GP, Jhala N. Solid-pseudopapillary neoplasm of the pancreas: Three cases with a literature review. Appl Immunohistochem Mol Morphol. 2006;14(4):445-53.

35. Deshpande V, Oliva E, Young RH. Solid pseudopapillary neoplasm of the ovary: a report of 3 primary ovarian tumors resembling those of the pancreas. Am J Surg Pathol. 2010;34(10):1514-20.

36. Stoll LM, Parvataneni R, Johnson MW, Gui D, Dorigo 0, Sullivan P. Solid pseudopapillary neoplasm, pancreas type, presenting as a primary ovarian neoplasm. Hum Pathol. 2012;43(8):1339-43.

37. Cheuk W, Beavon I, Chui DTY, Chan JKC. Extrapancreatic Solid Pseudopapillary Neoplasm. Int J Gynecol Pathol. 2011;30(6): 539-43.

38. Kosmahl M, Seada LS, Jänig U, Harms D, Klöppel G. Solid-pseudopapillary tumor of the pancreas: its origin revisited. Virchows Arch. 2000;436(5):473-80.

39. Yagcı A, Yakan S, Coskun A, Erkan N, Yıldırım M, Yalcın E, et al. Diagnosis and treatment of solid pseudopapillary tumor of the pancreas: experience of one single institution from Turkey. World J Surg Oncol. 2013;11:308.

40. Patnayak R, Jena A, Parthasarathy S, Vijaylaxmi B, Lakshmi AY, Rukmangadha $\mathrm{N}$, et al. Solid and cystic papillary neoplasm of pancreas: A clinic-pathological and immunohistochemical study: A tertiary care center experience. South Asian J cancer. 2013;2(3): 153-7.

41. Notohara K, Hamazaki S, Tsukayama C, Nakamoto S, Kawabata K, Mizobuchi K, et al. Solid-pseudopapillary tumor of the pancreas: immunohistochemical localization of neuroendocrine markers and CD10. Am J Surg Pathol. 2000;24(10):1361-71.

42. Lai J, Fan X, Guindi M, Balzer B, Rutgers JK. Endoscopic ultrasound guided - fine needle aspiration (EUS-FNA ), in comparison with gross and histologic diagnoses of pancreatic lesions. Am J Dig Dis. 2014;1(2):68-83.

43. Cai Y-Q, Xie S-M, Ran X, Wang X, Mai G, Liu X-B. Solid pseudopapillary tumor of the pancreas in male patients: report of 16 cases. World J Gastroenterol. 2014;20(22):6939-45.

44. Cai Y, Ran X, Xie S, Wang X, Peng B, Mai G, et al. Surgical management and long-term follow-up of solid pseudopapillary tumor of pancreas: a large series from a single institution. J Gastrointest Surg. 2014;18(5):935-40.

45. Lee JH, Yu J-S, Kim H, Kim JK, Kim TH, Kim KW, et al. Solid pseudopapillary carcinoma of the pancreas: differentiation from benign solid pseudopapillary tumour using CT and MRI. Clin Radiol. 2008;63(9):1006-14. 